\title{
Audit of energy provision by intensive care nasogastric feeding protocol compared with energy requirements at time of assessment
}

\author{
Carolyn Speirs and Maddy Hopkinson \\ Royal Bolton Hospital NHS Foundation Trust, Minerva Road, Bolton BL4 OJR, UK
}

Unless contra-indicated, enteral nutrition should be given to all ICU patients who are not expected to be taking a full oral diet within three days, commencing during the first $24 \mathrm{~h}$ using a standard feed ${ }^{(1)}$. At Bolton, as is common practice on ICU, this is achieved by following a standard NG feeding protocol, until patients are assessed by the dietitian. The protocol commences at $22 \mathrm{ml} / \mathrm{h}$ of standard feed, increasing to $63 \mathrm{ml} / \mathrm{h}$ if tolerated, feeding continuously $24 \mathrm{~h} / \mathrm{d}$.

During the acute and initial phases of critical illness, an energy supply in excess of $83.68-104.6 \mathrm{~kJ} / \mathrm{kg}$ BW/d (20-25 kcal/kg BW/d) (or to BMR) should be avoided ${ }^{(1)}$. 'Overfeeding' is associated with a poorer clinical outcome ${ }^{(2)}$. Therefore, to test the suitability of Bolton's ICU feeding protocol, target energy provisions for patients admitted to ICU (BMR, with deductions for propofol calories, obesity adjustment and estimated oedema or ascities ${ }^{(3)}$ ) were compared with potential energy provision from the NG feeding protocol at full rate.

Patients were identified retrospectively from 35 consecutive new admissions to be assessed by the dietitian. Six were excluded as they were not being enterally fed. The selected patients were a diverse group, including 11 men and 18 women, from 41 to 86 years of age and weighing from 48 to $134.5 \mathrm{~kg}$.

Energy requirements of men ( $n$ 11) varied from 4991.512 to $8501.888 \mathrm{~kJ} / \mathrm{d}$ (1193 to $2032 \mathrm{kcal} / \mathrm{d}$ ). The feeding protocol at full rate would meet from $78 \%$ to $121 \%$ of these requirements, potentially 'overfeeding' two. Energy requirements of women ( $n$ 18) varied from 3907.856 to $6589.8 \mathrm{~kJ} / \mathrm{d}$ (from 934 to $1575 \mathrm{kcal} / \mathrm{d}$ ). The feeding protocol at full rate would meet from $100 \%$ to $169 \%$ of these requirements, potentially 'overfeeding' 16 .

Because of risks of overfeeding, energy provision by the protocol at a lower feeding rate of $42 \mathrm{ml} / \mathrm{h}(4393.2 \mathrm{~kJ} / \mathrm{d}(1050 \mathrm{kcal} / \mathrm{d})) \mathrm{was}$ compared with the energy requirements of women. This was found to more closely match the energy requirements, but at the expense of reduced nutrient provision.

\begin{tabular}{lccc}
\hline Gender & Target energy from feed & $\begin{array}{c}\% \text { Target energy provided by } \\
\text { NG protocol at } 63 \mathrm{ml} / \mathrm{h}\end{array}$ & $\begin{array}{c}\% \text { Target energy provided by } \\
\text { NG protocol at } 42 \mathrm{ml} / \mathrm{h}\end{array}$ \\
\hline $\begin{array}{l}\text { Male } \\
(n 11)\end{array}$ & $\begin{array}{c}6748.792 \mathrm{~kJ}(1613 \mathrm{kcal}) \\
(\text { range: } 5439.2-8501.888 \mathrm{~kJ} \\
(1300-2032 \mathrm{kcal}))\end{array}$ & $\begin{array}{c}\text { (range } 78-121) \\
(\text { range } 52-81)\end{array}$ \\
$\begin{array}{l}\text { Female } \\
(n 18)\end{array}$ & $\begin{array}{c}4983.144 \mathrm{~kJ}(1191 \mathrm{kcal}) \\
(\text { range: } 3907.856-6589.8 \mathrm{~kJ} \\
(934-1575 \mathrm{kcal}))\end{array}$ & $\begin{array}{c}135 \\
(\text { range } 100-169)\end{array}$ \\
\hline
\end{tabular}

On the basis of data from this audit, the existing feeding protocol continued unchanged for men, feeding up to $63 \mathrm{ml} / \mathrm{h}$ over $24 \mathrm{~h}$ of standard feed (Jevity 1.0). The protocol was adapted for women, feeding up to a just $42 \mathrm{ml} / \mathrm{h}$, and replacing standard feed with Jevity Promote, which is nutritionally complete in the volume provided over $24 \mathrm{~h}$.

1. Kreymann KG et al. (2006) Clin Nutr 25, 210-223.

2. Jeejeebhoy KN (2004) Nutr Clin Pract 19(5), 477-480.

3. PENG (2007) A Pocket Guide to Clinical Nutrition, 3rd edn [V Todorovic and A Micklewright, editors]. 